\title{
Undergraduate Research Supervision: A Case Study of Supervisors' Perceptions at Yanbu University College
}

\author{
Suzan Hasan Al-Doubi ${ }^{1}$, Hala Fawzi ${ }^{2} \&$ JoDee Walters $^{3}$ \\ ${ }^{1}$ Yanbu Uinverstiy College, Royal Commission at Yanbu, Yanbu Industrial City, Kingdom of Saudi Arabia \\ ${ }^{2}$ English Language Education Division, Bahrain Teachers College, University of Bahrain, Kingdom of Bahrain \\ ${ }^{3}$ Yanbu Uinverstiy College, Royal Commission at Yanbu, Yanbu Industrial City, Kingdom of Saudi Arabia \\ Correspondence: Suzan Hasan Al-Doubi, Yanbu University College, Yanbu Industrial City, P.O. Box 31387, \\ Postal Code: 41912, Kingdom of Saudi Arabia. Tel: 966-553-555-367. E-mail: aldoubis@ rcyci.edu.sa
}

Received: September 2, 2019

doi:10.5539/hes.v9n4p112

\author{
Accepted: October 1, 2019 Online Published: October 9, 2019 \\ URL: https://doi.org/10.5539/hes.v9n4p112
}

\begin{abstract}
This exploratory case study examined supervisors' perceptions of supervision of undergraduate research projects, and whether the level of experience affects the quality of the supervision process. Data were collected through questionnaires and interviews. Participants were three supervisors with varying levels of experience in the supervision process at Yanbu University College in Saudi Arabia. Obtained themes were used with the whole data-set. The data were rearranged according to the emerged common themes among the three participants. Findings revealed that the level of experience affected the supervision process in relation to the supervisors" perceptions. It also suggested that the level of expereince of the supervisors influnced the process of supervision and the feedback given to the undergraduate students. An implication of these findings is that providing novice supervisors with training and guidance should be considered. Departments should create a discussion platform between experienced and novice supervisors to ensure that the supervision expereince is well delivered to undergraduates during their research projects. The study recommends supervisors to revisit all phases of their practice.
\end{abstract}

Keywords: undergraduate research, supervision, experienced supervisors, novice supervisors

\section{Introduction}

According to Brewer, Dewhurst and Doran (2012, p. 208), "undergraduate research forms an integral part of higher education and [in particular], the research project represents an important component of the undergraduate degree." Rubel and Okech (2006) state that describing supervisors' experiences during the undergraduate supervision process and whether and how supervisors give different types of feedback throughout the supervision process, as they gain experience, would provide essential information regarding their feelings, thought processes, and actions that could confirm and add to existing practices and models of supervision. For novice supervisors, in addition to the various challenges they face, there is no effective model of supervision to guide them closely in the process, to help them reflect on aspects of their responsibilities/roles as teachers and supervisors, and to evaluate their experience in terms of personal and professional development.

Moreover, novice supervisors' perceptions of undergraduate supervision and the initial practices of experienced supervisors clearly impact the supervision process and contribute to students' learning, especially when supervision is provided as part of teaching other courses and as part of their students' academic work. Borg (2009) suggests that to deepen the understanding of effective practice in the supervision process, there is a need for understanding both novice and experienced supervisors' conceptions of research, together with studying their perceptions about the different roles they, and their students, play during the supervision process.

Rowley and Slack (2004) highlight the importance of shedding light on the changing nature of the undergraduate research supervision experience, stating that the lack of a more proactive approach to supervisors' conception would lead to serious degradation of the supervision experience and outcomes. Vereijken, Rijst, Driel, and Dekker (2018) lay emphasis on what novice supervisors do to support student learning in undergraduate research projects and "why they do what they do in student-supervisor interaction," prioritizing the need for "adapting supervision to student characteristics or traits in practice" (p.523). 
In particular, the duality of the variety of roles taken by both supervisors and students during the supervision process has been highlighted in the literature. A supervisor may take on many roles, "acting as a guide, confidant consultant, and examiner" (MacKeogh, 2006, p.20), a "resource person, directing students to references and contacts, discussing ideas and work undertaken" (Armstrong \& Shankar, 1983, p.177), or like "a teacher, counsellor, facilitator, and consultant" (Rubel \& Okech, 2006, p.117). However, supervisors' and students' roles and responsibilities should be clear from the early stage of the supervision process (Abiddin, Hassan, \& Ahmad, 2009).

In Jamieson and Gray's (2006) study, supervisors described their perceptions of effective supervision, particularly how to balance various supervision roles, as teaching, mentoring, supporting, challenging, and evaluating, to facilitate effective learning for students in diverse contexts. On the other hand, Brewer et al. (2012) demonstrated that supervisors stressed the roles of support during supervision in assisting students by giving effective feedback and supporting students' efforts that framed supervisors' commitments and actions.

However, some challenges may take the supervision process toward certain directions, such as worrying about supervisor's roles/responsibilities (MacKeogh, 2006), defining supervisors-student relationship (Roberts \& Seaman, 2018), being confused about their feelings (Rubel \& Okech, 2006), and providing high-quality research experiences for undergraduates (Pfund, Pribbenow, Branchaw, Lauffer, \& Handelsman, 2006). These differences in the perception of different concepts in the supervision process highlight the need for "adequate support [which] can enable novice supervisors to deliberately use and learn from their personal supervision experiences" (Vereijken et al., 2018, p.523).

Brewer et al. (2012) stated that, regardless of the type of feedback, either oral or written, the role of supervisors is emphasized by giving effective feedback and supporting students. Researchers such as Pfund et al. (2006) highlighted the necessity for new supervisors to get "proper training...to ensure that new advisors are prepared to provide high-quality research experiences for undergraduates" (p.473). Exploring the type of feedback provided by both experienced and inexperienced supervisors could provide descriptions that are useful in defining undergraduate supervision practices (Roberts \& Seaman, 2018), in addition to playing a role in expanding existing supervision practices to improve the process.

Although there are studies addressing the supervision process of undergraduate research project, the practice of undergraduate research supervision is an understudied area of higher education in Saudi Arabia, even though many universities in Saudi Arabia are offering research programs for undergraduate students in Applied Linguistics (AL) departments. The supervision process in Saudi Arabian universities has not been investigated in terms of whether supervisors' level of experience has an impact on their engagement in the process of supervising undergraduate research projects, how supervisors perceive the process of supervision and their perceptions of how it ought to be, or how their level of experience affects the quality of feedback they provide to undergraduate research students. Furthermore, to the best of the researchers' knowledge, there is no study that examines either the perceptions or the initial experiences of novice supervisors of undergraduate research projects. Hence, we sought to address this gap by examining experienced and novice supervisors' perspectives on the process of supervision of undergraduate research projects.

This study aims to examine the perceptions of supervisors working in the AL Department at Yanbu University College (YUC) about the process of supervision of undergraduate research projects. The purpose of the study is to provide an in-depth exploration of the effect of experience on supervisors' perspectives in supervising undergraduate research projects prior to, during, and after the supervision process. It also aims to explore how both experienced and novice supervisors perceive their role in managing the multiple tasks and responsibility level of a supervisor, while paying attention to students' roles in a way that enables students' development in conceptualizing the idea of conducting research. The findings are expected to help in building a foundation for further research on effective undergraduate research supervision.

The research questions addressed in this study are as follows:

1. What are the perceptions of supervising faculty members with varying levels of experience, of the process?

a. What are their perceptions of their own roles and/or responsibilities in the process?

b. What are their perceptions of the roles and/or responsibilities of the students?

2. How do faculty members at YUC, with varying levels of experience with the supervision process, conduct the supervision? 
3. What is the nature of the feedback given by supervising faculty members with varying levels of experience?

4. Do the perceptions of supervising faculty members at YUC change over the time period of the supervision?

5. Does the level of experience with the process influence the way the supervision is conducted, the nature of the feedback given, and the perceptions of the process?

\section{Method}

\subsection{Setting and Participants}

This study is an exploratory case study, with qualitative data collected through questionnaires and interviews. The study was carried out during one semester in the Applied Linguistics Department at Yanbu University College (YUC), an English-medium college in Yanbu Industrial City, Kingdom of Saudi Arabia. The Applied Linguistics Department offers a four-year Bachelor of Science in Applied Linguistics to female Saudi undergraduate students. In the final semester of the program, students are required to complete a research project, exploring an issue in Applied Linguistics through research. Purposeful sampling was used in selecting the participants. The participants in the study were three instructors who worked as supervisors to a small group of students completing their research projects. The participants were all females, and all had been teaching at YUC for several years, ranging from four to nine years. All participants held MA Degrees in an area of Linguistics or Applied Linguistics. The participants are described individually below:

Participant 1 holds Master of Arts in Linguistics, and had been a teacher for 17 years at the time of the study, the last eight years at YUC. She had been supervising senior students' research projects for the last five years.

Participant 2 holds Master of Arts in TESOL, and had been a teacher for nine years at the start of the study. For a period of one year, she had supervised senior students' research projects, but was not involved in the following academic year.

Participant 3 holds Master of Arts in Translation, and had been a teacher for four years when the study began. Until the semester in which the study began, she had never worked as a supervisor for research projects, although she had helped senior students several times with choosing a topic and developing a proposal when their topics involved the area of translation.

\subsection{Instrumentation}

The qualitative questionnaire consisted of a brief explanation of the steps that students would go through in their senior research projects, followed by four open-ended questions about the supervisors' perceptions of the supervision process. The first questionnaire also included five questions seeking demographic information about the participants, including level of education and specialization, teaching experience, and experience with the supervision process. Content and face validity were examined by two experts in the field of research at YUC. Moreover, member checking took place after conducting the interviews. The participants were asked to verify the transcribed interviews to validate the accuracy of their responses.

\subsection{Data Collection Procedure}

The participants were selected based on their level of experience in supervising senior research projects. Our aim was to select one experienced supervisor, one with some limited previous experience who would be returning to the process of supervision, and one teacher who would be new to the experience of supervising. All the participants agreed to take part in the study and agreed to fill out questionnaires and participate in interviews. Additionally, quotes and in-depth descriptions were used.

Before the beginning of the semester, participants were sent an email with a questionnaire. They were asked to fill in and email the completed questionnaire before the beginning of the semester. Upon receiving the completed questionnaires, the researchers compiled a set of follow-up questions for each faculty member, and then conducted interviews. The interviews were conducted in the first week of the semester. Two researchers were present during each interview, one taking the lead in asking questions, and one taking notes and asking occasional follow-up or clarification questions. During the interview, the faculty member had access to her completed questionnaire, as a reminder of the responses she had given. The interviews were recorded and then transcribed.

About two months after the faculty members had begun the supervision process with their students, a second questionnaire was delivered to them by email. This questionnaire asked essentially the same questions as on the first questionnaire, but then the participants were asked if their perceptions were still the same, or had they 
changed, after having been supervising their students for the past two months. Again, they filled out the questionnaires and returned them by email.

It had been our intention to conduct follow-up interviews after the second questionnaire, and then to conduct another round of questionnaires followed by an interview at the end of the semester, but the pressures of the semester experienced by the teachers led us to eliminate the second interview and the third questionnaire, opting instead for a final interview after the semester was over.

The final interview was conducted near the beginning of the following semester, when all the work from the previous semester was completed. As with the previous interview, the participants' responses to the questionnaire (in this case, the second questionnaire) served as the basis for follow-up questions in the interview. In addition, the participants were asked to reflect on the experience and comment on what, if anything, they would do differently. As before, there were two researchers present during the interviews, and the interviews were recorded and transcribed.

\section{Results and Discussion of Qualitative Data}

The process of data analysis took place by reviewing each transcribed interview and questionnaire repeatedly to identify codes. Those overlapping codes being recognized from all analyzed data were compared. As a result, themes emerged in relation to the experiences of the three participants about their process of supervision of the research project.

\subsection{Supervisors' Perceptions of their Roles}

The first research and sub-question(s) that guided this study were: What are the perceptions of supervising faculty members with varying levels of experience, of the process? (a) What are their perceptions of their own roles and/or responsibilities in the process? Regardless of level of experience, all supervisors viewed their expected role of supervision as 'guidance.' Participant 1 stated that her role was as "one who provides guidance throughout the research project." She described this guidance as "assist[ing] the student in choosing a suitable research topic and planning a good research methodology. Probes the students to look for answers on their own. Having regular meetings for monitoring the progress and clearing any doubts." Participant 2 indicated that "the role of the supervisor is mainly to guide the student as she embarks on this task." She explained that the process of guidance includes "be[ing] there to support and advise the student to steer her in the right direction." For Participant 3, she elaborated that her role was "guiding the student and working closely with her all through the journey of writing the research project." The theme of guidance is consistent with MacKeogh (2006, p.20), where "acting as a guide" was one of the findings.

Moreover, some subthemes under guidance were derived. They included: (a) "to support students," (b) "be available to answer questions," (c) "to remind students of deadlines," (d) "motivate students," (e) "to point out areas of improvement." Only the novice supervisor (Participant 3) mentioned the need to:

build mutual trust between me and the students. As it is very important for students to trust the supervisor in order to accept the guidance and to have a harmonious work team which will bring the best results at the end.

One can infer that her mention of building mutual trust between herself as a supervisor and the student may be a result of her being new to the experience of the process of supervision.

\subsection{Supervisors' Perceptions of Students' Roles}

The second sub-question was: (b) What are their perceptions of the roles and/or responsibilities of the students? The identified theme that the participants agreed upon was that the student had to be an 'autonomous learner.' However, each participant described all the tasks that her students should do differently; their perceptions ranged from a detailed list to a holistic or brief explanation, about the students' responsibilities/roles. For example, Participant 1 suggested that the student should "be punctual, attend all meetings, maintain a record of their progress, understand the meaning of plagiarism, and meet deadlines."

The second participant explained the role of the student as: to "take advantage of the resources available, pace herself, and keep her supervisor informed of her progress and issues." Participant 3 indicated that the student should be "responsible for her research from $\mathrm{A}$ to $\mathrm{Z}$ in terms of collecting data, finding sources, mastering the research tools, presenting ideas, and following the writing style." Moreover, she was the only supervisor who mentioned that her students should show a "positive attitude" during their meetings. Again, this could be attributed to her being novice to the field of supervision leading her to hold some expectations of students' performance, not only related to coursework but also to personal attitudes, unlike the other more experienced 
supervisors. The theme of viewing students' roles as autonomous learners is in line with Abiddin et al. (2009), where they need to fulfill that role during working on their research projects.

\subsection{Impact of Supervisors' Level of Experience}

The second research question of this study was: How do faculty members at YUC with varying levels of experience of the supervision process conduct the supervision? The findings that answer this research question focused on three main themes: "meet with students regularly," "follow up progress," and "give feedback." Interestingly, the findings were expressed differently from one supervisor to the other depending on the level of experience of supervision. Participant 1 discussed the process of supervision in detail. She knew what she was doing in the sense that every stage was included, starting from choosing a topic, searching in related literature, designing the research methodology, discussing tools, data collection, data analysis and findings, and finally giving feedback to the various drafts until the end of the process where the student prepares for the final presentation of her research project.

On the other hand, Participant 2, a returning supervisor to the process, was very brief. She indicated that:

$[\mathrm{P}]$ reviously, I allowed students to contact me as they had been given a timeline. However, I believe that this time I would like to meet with my students and discuss what I expect from them and what they can expect from me.

This indicates that her perception of the supervision process had changed, as she intends to take a more active role this time, rather than simply letting the students contact her when they feel the need. She focused more on meeting the students and identifying students' roles and hers, rather than allowing them to contact her when they needed to do so.

Conversely, as a novice supervisor, Participant 3 highlighted that the supervision process was new to her. She emphasized that she wanted to "get the utmost of this experience" by "following the handbook of the course as closely as possible and observing my experienced colleagues and the course leader through the sessions that they are planning to give at the beginning of the course." She adds:

Also, I will make my own blueprint for guiding my students and I will make sure that my plan will align with my colleagues' in the overall structure....... I will have to guide with my own compass and at the same time to check regularly with the course leader and my other colleagues. I believe it will be a very good opportunity for me to learn from their expertise in the whole experience of supervision.

Even though Participant 3 insisted that she will follow the course leader and colleagues on one hand, she indicated that she will make her "own blueprint" and guide with her "own compass" on the other hand. Such a striking contradiction between her perception/plan and action/ implementation is a clear reflection of her lack of experience. Interestingly, the novice supervisor suggested using "some useful self-tutorial resources from social media like Twitter, Facebook, and YouTube on how to write a final research project." Neither of the other two participants made the same suggestion. This may be attributed to her being the youngest among the three participants, one of the new generation who strongly support the integration of technology in teaching and learning.

This finding indicates that there may be differences in perceptions of the supervision process due to the varying levels of experiences in supervising undergraduate research. It supports the finding by Vereijken et al. (2018, p. 523) that identified the need for "adequate support [which] can enable novice supervisors to deliberately use and learn from their personal supervision experiences." Such support is essential, due to "the changing nature of undergraduate research supervision process" (Rowley \& Slack, 2004, p. 2).

\subsection{Supervisors' Given Feedback}

In relation to the third research question, which asked about the nature of feedback given by supervisors with varying levels of experience, the emerged theme varied among supervisors between 'oral' and 'written' feedback. Participant 1 favored providing oral feedback through asking questions "about their work instead of providing simple feedback. Questions would cover all areas." By doing so, she would "check the originality of the work produced by the students." She determined that "doing this will help the students to realize their strengths and weaknesses" while giving feedback to content, organization, research principles, and language. For the returning supervisor, Participant 2, feedback was directed toward "organization" and "language." This focus on certain types of feedback was also shared by the novice supervisor, who concentrated on "content and language." Both participants put more emphasis on giving written feedback. 


\subsection{Impact of Time on Supervisors' Perceptions}

To answer the fourth research question of whether the perceptions of supervising faculty members at YUC changed over the time period of supervision, the second questionnaire and interview were analyzed. The emerged theme reinforced that "time did not play much role" on the supervisors" perception of the supervision itself. For the experienced supervisor, no change was encountered in the process of supervision. She stated "My perceptions are more or less the same. I can explain my point of view by sharing my experience with the students of this semester... I did whatever I planned in the beginning and my students followed the deadlines." Similarly, the novice supervisor said that she was going "with the flow" and "did not plan differently." She kept following the guidance provided to her through her colleagues, "the course leader's vision and the course structure." Yet, she believed that next time she "will supervise with more confidence than my first time. I just need some time to adapt more into the research culture."

The returning supervisor argues that even though she considered the supervision process was mainly to guide, she noticed, after working with her students that "at times I needed to be a motivator when they became discouraged." She extended her perception of supervision to be:

available to answer their questions and help keep students on track. I also found that I needed to educate myself more on their topics. If the supervisor is not familiar with a topic, she may need to do some research herself which may help the student with finding and selecting suitable sources.

\subsection{Impact of Level of Experience on the Overall Supervision Process}

The last research question was: Does the level of experience with the process influence the way the supervision is conducted, the nature of the feedback given, and the perceptions of the process? After analyzing the collected data, the findings suggest that level of experience had a possible impact on the supervision process in relation to the perception, the process, and the feedback given. The experienced supervisor did what she planned for in relation to the supervision process and feedback, which aligned with her perception. For the returning supervisor, she indicated change among the three participants. She started the supervision by depending on her previous experiences. However, that changed over time, as illustrated by this quote:

Previously, I simply was not sure of anything other than the fact that I believed that the student's role was 'the researcher.' It is her job and responsibility to do the work. I do still believe this is the case in addition to the points mentioned above (her quote that answers the fourth research question).

Moreover, her written feedback started at one point where the focus was on language. She said, "I would tell myself to focus less on the language and more on the research design." Her focus changed to research design, as can be seen in the following:

I believe that feedback in the future will be from top to bottom, with the focus first being on research principles, content, organization and then language. Once we are satisfied with the research principles, we can move on to the next step. And if one student requires attention in a different area, we will work on that.

Finally, it was apparent that the novice supervisor depended totally on following the structure of the course, the course leader, and her colleagues. She insisted on "check(ing) regularly with the course leader and other colleagues." She believed that "it will be very good opportunity for me to learn from their expertise in the whole experience of supervision." Furthermore, by doing so, the novice supervisor declared that she had not had "that much trouble" in guiding her students because...

the course was shared by other supervisors whom I could double check with whenever I needed' and best of all of the supervisors were guided by the instructions and workshops given by the course leader. Every aspect of supervision has been taken care of by the course leader. I only guided my students in terms of discussing their topics and designing research questions at the beginning and then through the given feedback on how to collect data, conduct their tests and the language used.

This finding pinpoints the need to train novice supervisors, which aligns with Pfund et al. (2006), who highlighted the importance of equipping novice supervisors with proper training to guarantee high-quality research experiences for undergraduates. 


\section{Conclusion}

This study aimed to explore supervisors' perceptions of the supervision process of undergraduate applied linguistics research projects. It also examined whether the level of experience played a role in the quality of the supervision process. The study was an exploratory case study where qualitative data were collected through questionnaires and interviews. The findings show that while supervisors viewed their role as guidance providers, they viewed students' role as autonomous learners who conduct the research themselves. Moreover, the results suggest that the level of experience influenced the perception of the supervisors, the process of supervision, and the type of feedback given to the students. In other words, the experienced supervisor was determined and confident in relation to every step of the process of supervision, her role, students' role, the feedback she gave; the returning supervisor used her past experience to guide her when interacting with students in relation to roles and responsibilities, the process of supervision, and given feedback. Nonetheless, she extended and directed her attention to be more focused on certain elements rather than the other, such as research design rather than language and organization. Finally, the novice supervisor was also focused on the elements of supervision. However, she kept following the footprints of the course leader, colleagues, and the course structure/ manual.

Through sharing perceptions of supervisors with various levels of experience about their roles and their students' roles, departments and institutions can utilize the knowledge of experienced supervisors to mentor and guide novice supervisors to develop a better learning experience for undergraduate students undertaking research projects. Hence, it is recommended that institutions/ departments pay more attention to novice supervisors when assigning the research course to them. They need to create a platform of discussion between novice and experienced supervisors through sharing experiences and following up on their progress. Moreover, since the sample size consisted of three participants, it is hard to generalize the above findings. Therefore, it is recommended to conduct further research with a larger number of participants. It is also recommended to implement different research methods, since the nature of this study was a case study design to have better understanding of the undergraduate supervision process.

\section{References}

Abiddin, N., Hassan, A., \& Ahmad, A. (2009). Research student supervision: An approach to good supervisory practice. The Open Education Journal, 2, 11-16. https://doi.org/10.2174/1874920800902010011

Armstrong, M., \& Shanker, V. (1983). The supervision of undergraduate research: Student perceptions of the supervisor role. Studies in Higher Education, 8(2), 177-183. https://doi.org/10.1080/03075078312331379044

Borg, S. (2009). English language teachers' conceptions of research. Applied Linguistics, 30(3), 358-388. https://doi.org/10.1093/applin/amp007

Brewer, G., Dewhurst, A., \& Doran, D. (2012). Undergraduate research projects: Practice and perceptions. Psychology Learning and Teaching, 11(2), 208-217. http://dx.doi.org/10.2304/plat.2012.11.2.208

Jamieson, S., \& Gray, C. (2006). The supervision of undergraduate research students: Expectations of student and supervisor. Practice and Evidence of the Scholarship of Teaching and Learning in Higher Education, 1(1) 37-59. Retrieved from http://community.dur.ac.uk/pestlhe.learning/index.php/pestlhe/article/view/125/142

MacKeogh, K. (December, 2006). Supervising undergraduate research using online and peer supervision. In: M. Huba (Ed.). Paper presented at the seventh International Virtual University Conference, pp. 19-24, Bratislava, Technical University Bratislava. Retrieved from http://doras.dcu.ie/82/

Pfund, C., Pribbenow, C. M., Branchaw, J., Lauffer, S. M., \& Handelsman, J. (2006). The merits of training mentors. Science, 311(5760), 473-474. https://doi.org/10.1126/science.1123806

Roberts, L., \& Seaman, K. (2018) Good undergraduate dissertation supervision: Perspectives of supervisors and dissertation coordinators. International Journal for Academic Development, 23(1), 28-40. https://doi.org/10.1080/1360144X.2017.1412971

Rowley, J., \& Slack, F. (2004). What is the future for undergraduate dissertations? Education and Training, 46(4), 176-181. https://doi.org/10.1108/00400910410543964

Rubel, D., \& Okech, J. (2006). The supervision of group work model: Adapting the discrimination model for supervision of group workers. Journal for Specialists in Group Work, 31(2), 113-134. https://doi.org/10.1080/01933920500493597

Vereijken, M., Rijst, R., Driel, J., \& Dekker, F. (2018). Novice supervisors' practices and dilemmatic space in 
supervision of student research projects. Teaching in Higher Education, 23(4), 522-542.

https://doi.org/10.1080/13562517.2017.1414791

\section{Copyrights}

Copyright for this article is retained by the author(s), with first publication rights granted to the journal.

This is an open-access article distributed under the terms and conditions of the Creative Commons Attribution license (http://creativecommons.org/licenses/by/4.0/). 